\title{
Intensity-Modulated Radiotherapy versus 3-Dimensional Conformal Radiotherapy Strategies for Locally Advanced Non-Small-Cell Lung Cancer
}

\author{
Uğur Selek ${ }^{1,2}$, Yasemin Bölükbaşı ${ }^{2}$, James W. Welsh², Erkan Topkan ${ }^{3}$ \\ ${ }^{1}$ Department of Radiation Oncology, Koç University Faculty of Medicine, İstanbul, Turkey \\ ${ }^{2}$ Department of Radiation Oncology, University of Texas M.D. Anderson Cancer Center, Texas, USA \\ ${ }^{3}$ Department of Radiation Oncology, Başkent University Adana Faculty of Medicine, Adana, Turkey
}

Chemoradiotherapy is the current standard of care in patients with advanced inoperable stage IIIA or IIIB non-small cell lung cancer (NSCLC). Three-dimensional radiotherapy (3DCRT) has been a trusted method for a long time and has well-known drawbacks, most of which could be improved by Intensity Modulated Radiotherapy (IMRT). IMRT is not currently the standard treatment of locally advanced NSCLC, but almost all patients could benefit to a degree in organ at risk sparing, dose coverage conformality, or dose escalation. The most critical step for a radiation oncology department is to strictly evaluate its own technical and physical capabilities to determine the ability of IMRT to deliver an optimal treatment plan.
This includes calculating the internal tumor motion (ideally 4DCT or equivalent techniques), treatment planning software with an up-todate heterogeneity correction algorithm, and daily image guidance. It is crucial to optimise and individualise the therapeutic ratio for each patient during the decision of 3DCRT versus IMRT. The current literature rationalises the increasing use of IMRT, including 4D imaging plus PET/CT, and encourages the applicable knowledge-based and individualised dose escalation using advanced daily image-guided radiotherapy.

Key Words: 3-D conformal radiotherapy, intensity modulated radiotherapy, lung cancer
In the evolution of radiation oncology technology, improved planning and treatment delivery advanced from two-dimensional radiotherapy (2DRT) to three-dimensional conformal radiotherapy (3DCRT) two decades ago. In the last decade, intensity-modulated radiation therapy (IMRT) emerged in addition to daily image guidance and fourdimensional (4D) image-based motion management (1). Chemoradiotherapy, which was actually established mainly with a 2DRT trial-RTOG 9410, is the current standard of care in patients with inoperable stage IIIA or IIIB non-small cell lung cancer (NSCLC) when compared to sequential protocols (2-7). Currently, aggressive chemoradiotherapy is the standard, and is well accepted in highly selected septuagenarians with inoperable stage IIIB NSCLC (8). Conventional doses (60-63 Gy) of 3DCRT were well-thought-out not enough to succeed for desired local control to avoid dismal survival. There has been a significant challenge in safely escalating the radiation dose over $60 \mathrm{~Gy}$, while preserving the critical organ at risk (OAR) structures (9-12). In the last decade, IMRT has been the leading improvement, and has been considered as the key solution for safe dose escalation and delivery. Other accompanying challenges are the fight with unpredictable movement of the tumor during the respiratory phases, the need to increase the accuracy of treatment delivery during each fraction, and the necessity to clarify the heterogeneity correction in treatment planning systems. The newest technology has been improved upon in recent years by $4 \mathrm{D}$ image-based motion capturing and the management of treatment planning, the evolution of calculation algorithms in treatment planning systems that are capable of better estimating the dose delivery to tumors and normal structures, and image-guided radiotherapy. All of these improvements increased the daily setup accuracy. There is a requirement for radiotherapy is evident in NSCLC, with than $60 \%$ of these patients requiring radiotherapy during treatment, and more than $40 \%$ of patients who receive radiotherapy receive it during the initial treatment $(13,14)$. Therefore, due to the growing struggle with lung cancer, the current debate, based on inclusion of all modern technology, is whether IMRT has an advantage over 3DCRT in the outcomes of local control, sur-

Address for Correspondence: Dr. Uğur Selek, Department of Radiation Oncology, Koç University Faculty of Medicine, İstanbul, Turkey

Phone: +90 4443777 e-mail: ugurselek@yahoo.com

Received: 18.06.2014 Accepted: 13.09.2014 Available Online Date: 13.09.2014 • DOI: 10.5152/balkanmedj.2014.14529

Available at www.balkanmedicaljournal.org

Selek U, Bölükbaşı Y, Welsh JW, Topkan E. Intensity-modulated radiotherapy versus 3-dimensional conformal radiotherapy strategies for locally advanced non-smallcell lung cancer. Balkan Med J 2014;31:286-94. 
vival, and acute and late side effects (esophagitis and pneumonitis). IMRT is a technological improvement in the delivery of radiotherapy, which provides the potential to increase the target coverage while decreasing the doses to the organ at risk to well below complication thresholds (15). However, it unfortunately increases the cost of treatment.

The understanding of the tolerance of normal tissues, especially lung tissue, which is a dose limiting organ, has improved in last decade (16). As clinicians respect dose-volume constraints to reduce the acute and late side effects of radiotherapy, there is an ongoing effort in the quantitative analysis of radiotherapy effects on normal tissue for updated dose volume constraints, as well as generating atlases for decreasing inter-observer variability (17-19). Residual lung function after treatment is a major quality of life issue in lung cancer patients, as there are pretreatment compromises based on pre-existing comorbidities and the primary tumor (20). Chemoradiotherapy in locally advanced NSCLC also significantly affects lung function if the critical dose thresholds are not respected and the results for decreased lung function parameters determined by objective pulmonary function tests (PFTs) (21-23). Therefore, lung function preservation as a dose limiting factor was one of the major reasons for investigating lung IMRT, in order to spare as much parenchymal tissue as possible from higher doses.

The question of whether we need IMRT or not is strictly tied to questions of whether we need dose escalation, whether we need to decrease toxicity related with chemoradiotherapy, whether we have tools to manage tumor motion, whether we have adequate treatment planning software algorithms, or whether or not we have image guidance capabilities.

\section{SIGNIFICANCE OF DOSE ESCALATION IN LOCALLY ADVANCED NSCLC}

The dismal survival rate following a local recurrence in patients who completed their lung cancer radiotherapy is unfortunate (2). Machtay et al. $(9,10)$ reported on 11 RTOG trials including 1356 locally advanced NSCLC patients and documented locoregional failure rates of $46 \%$ and $52 \%$, and overall survival (OS) rates of $38 \%$ and $15 \%$ at two and five years, respectively. Locoregional control was recognised to be operative in long term survival of NSCLC patients (10). In order to improve the local regional control rates, many centers initiated dose escalation trials in stage III NSCLC patients to observe the feasibility and safety constraints of concurrent chemoradiotherapy with higher doses. Most concluded that 74 Gy was a tolerable dose in the well-controlled setups of 3DCRT (24-26). From a study including
106 NSCLC patients at the University of Michigan, Kong et al. (27) reasoned that each $1 \mathrm{~Gy}$ increment improved the five-year local control rate by $1.25 \%$ as decreasing the death risk by $3 \%$. This suggested that higher radiation doses were associated with better outcomes. Increasing the dose of radiation was reported to compensate the negative effect of large tumor volume in medically inoperable node-negative early stage NSCLC patients treated with radiotherapy alone (28). Zhao et al. (28) compared a biologically equivalent dose (BED) of $\leq 79.2$ Gy (physical dose of 66 Gy in 2-Gy daily fractions) versus $>79.2 \mathrm{~Gy}$, and reported that a gross tumor volume (GTV) of $>51.8 \mathrm{~cm}^{3}(\sim 4 \mathrm{~cm})$ caused shorter median OS rates of 18.2 months in comparison to 23.9 months with a GTV of $\leq 51.8 \mathrm{~cm}^{3}$, despite no survival difference based on tumor volume remained for who received a BED of $>79.2$ Gy. Moreover, patients with a GTV $>51.8$ $\mathrm{cm}^{3}$ had a chance of longer median OS rates (30.4 months) if they received a BED of $>79.2$ Gy in contrast to ones who received a BED of $\leq 79.2$ Gy (18.2 months). Wang et al. (12) emphasised in their retrospective review of the University of Michigan chemoradiotherapy data, that there was a 3\% reduction in the risk of death with 1 Gy of dose escalation in the range of 60-66 Gy. Memorial Sloan Kettering Cancer Center data published by Rengan et al. (11) reported a higher survival rate for patients receiving $\geq 64$ Gy than for ones receiving $<60 \mathrm{~Gy}$. Radiotherapy dose escalation along with concurrent chemotherapy in patients with stage III NSCLC was also indicated in the RTOG database by Machtay et al. $(9,10)$ to show increased local control and OS rates by a $1-$ Gy increase in BED. This was associated with an approximate relative improvement of $4 \%$ in survival and a relative improvement of 3\% in locoregional control. RTOG 94-10 compared 3-arms, including induction versus concurrent chemoradiation therapy at a standard dose of 60-63 Gy and at hyperfractionated 69.6 Gy delivered as twice-daily 1.2 $\mathrm{Gy} /$ fraction, and revealed that dose escalation with hyperfractionation of the $69.6 \mathrm{~Gy}$ arm had worse survival than the 60 Gy arm (3). Yuan et al. (29) reported a prospectively randomised dose escalation trial in patients with inoperable stage III NSCLC who were enrolled on 3DCRT of 1.8 to 2 Gy and 68 to 74 Gy for involved-field irradiation (IFI) covering the primary tumour and involved lymph nodes, or 60 to 64 Gy covering the primary tumour and involved lymph nodes, and elective nodal irradiation (ENI). Yuan et al. (29) documented a better outcome and local control, as well as lower radiation pneumonitis rates, in the dose escalated (6874 Gy) IFI arm than the 60 Gy ENI arm.

Almost all dose escalation trials in advanced NSCLC were performed using the $2 \mathrm{D}$ or $3 \mathrm{DCRT}$ technique without $4 \mathrm{D}$ image-based motion capability. There was always a question re- 
garding whether IMRT and tumor motion management would be more sustainable using dose escalation. The most recent RTOG 0617 trial in patients with stage III NSCLC comparing 60 Gy to 74 Gy 3DCRT concurrent with chemotherapy +/cetuximab in four arms of a $2 \times 2$ design closed accrual in the high-dose arm based on a planned interim analysis with higher dose crossing a futility boundary. However, a specific cause could not be determined and the reported toxicity was not in agreement with the lower survival rates in the high dose arm (30). As it does not seem rational to put aside all the accumulated data from the trials (9-12) and conclude that dose escalation is not beneficial, one can easily claim that 74 Gy could be too toxic when delivered by the limited radiation techniques in the trial without tumor motion management of $4 \mathrm{D}$ treatment planning, image guidance, and intensity-modulated radiotherapy (31).

\section{EVOLUTION IN IMRT}

Although RTOG 9410 paved the way for standardisation of chemoradiotherapy with better locoregional control and higher OS rates than sequential chemotherapy followed by radiotherapy regimens, adding concurrent chemotherapy increased the rate of grade 3 or higher toxicity $(50 \%$ versus $30 \%)$ in comparison with a sequential approach $(3,5,7)$. As an advancement over 2DRT, 3D-CRT has been reported to decrease toxicity in addition to allowing a dose escalation from $60 \mathrm{~Gy}$ to $74 \mathrm{~Gy}$ in concurrent chemoradiotherapy (24-26). IMRT is considered an innovation that can successfully reduce normal tissue toxicity in locally advanced NSCLC patients (32-40).

It has also become obvious that IMRT needs to be considered for high dose radiation to avoid overdose to normal tissues, which triggered dosimetric and clinical studies. As Marnitz et al. (41) at Charite Campus University Hospital in Berlin reported an average of a $16 \%$ possible dose escalation advantage with IMRT in comparison to 3DCRT. Grills et al. (32) reported a dosimetric benefit comparison performed in William Beaumont Hospital for IMRT versus 3DCRT, especially in node-positive patients and in those with adherence to the esophagus. They reported IMRT was capable of delivering 25-30\% greater radiotherapy doses than 3D-CRT under the same OAR constraints. Schwarz et al. (37) at The Netherlands Cancer Institute also called attention to a possible advantage of IMRT over 3DCRT. They saw an average dose increase as high as $35 \%$ with an evident benefit for large and concave tumors (37). Chapet et al. (38) in Lyon documented significant heart sparing with IMRT. Christian et al. (39) at the Institute of Royal Marsden reported that IMRT reduced the dose to the lungs and improve the conformity of the plan in dosimetric comparison to 3DCRT. Researchers from the MD Anderson Cancer Center noted that IMRT dosimetrically had the potential to decrease lung and esophageal toxicity, in addition to sparing the heart from higher doses (34, 35). Liu et al. (34) compared IMRT plans with the 3D-CRT plans for which V20 and mean lung dose were reduced for all cases, with median reductions of $8 \%$ and $2 \mathrm{~Gy}$, respectively. Murshed et al. (35) also noted that IMRT decreased the V10 and V20, which corresponded to a reduction of $>2$ Gy in the mean total lung dose and a $10 \%$ probable reduction in the risk of radiation pneumonitis. They also reported decreased volumes of the heart and esophagus irradiated to $>40-50$ Gy. IMRT dosimetrically sound more suitable than 3DCRT in advanced-stage disease with large and complicated gross tumor volumes, as well as in adherence to critical structures $(34,35)$.

Although there is no randomised trial comparing IMRT and 3DCRT, there are two reliable reports from the MD Anderson Cancer Center that retrospectively compared a single study center that treated patients in years with a substantial overlap of patients: 290 patients (222, 3DCRT versus 68, IMRT) between 2000-2005 by Yom et al. (15) and 409 patients (318, 3DCRT versus 91, IMRT) between 1999-2006 by Liao et al (42). The common emphasis in both manuscripts was the reduction in critical threshold doses of OAR and clinical side effects directly related with the quality of life. Yom et al. (15) noted the good correlation of the percentage of total lung volume reduction in patients receiving doses of at least 20 Gy radiation (V20; $38 \%$ with a range of $8-78 \%$ in 3DCRT versus $35 \%$ with a range of $20-48 \%$ in IMRT, $p<0.001$ ), and the reduction in $\geq$ grade 3 treatment-related pneumonitis (TRP; $32 \%$ at 12 months in 3DCRT versus $8 \%$ at 12 months in IMRT, $\mathrm{p}=0.002$ ) in favor of IMRT. Liao et al. (42) also indicated the significant reduction in $\geq$ grade 3 TRP rates by IMRT (approximate numbers derived from figures, $\sim 25 \%$ at 12 months in 3DCRT versus $\sim 10 \%$ at 12 months in IMRT, $\mathrm{p}=0.017$ ). Liao et al. (42) also documented the overall outcome of two cohorts of 3DCRT with conventional CT versus IMRT with 4DCT planning in favor of IMRT with a significant (median survival, 10.2 months in 3DCRT versus 16.8 months in IMRT, $\mathrm{p}=0.039$ ) OS rate difference, which could not be directly attributed to IMRT.

Overall, all reports comparing 3DCRT and IMRT revealed that IMRT has the spirits to spare normal tissues from higher doses of radiotherapy in order to decrease the notable side effect rates, which is in agreement with the potential of dose escalation for local control goals. Therefore, it is not fair to ask which treatment technique is better. Based on the ability of IMRT to deliver higher doses with concave or sharp dose falloffs on critical structures with the potential for organ preserva- 


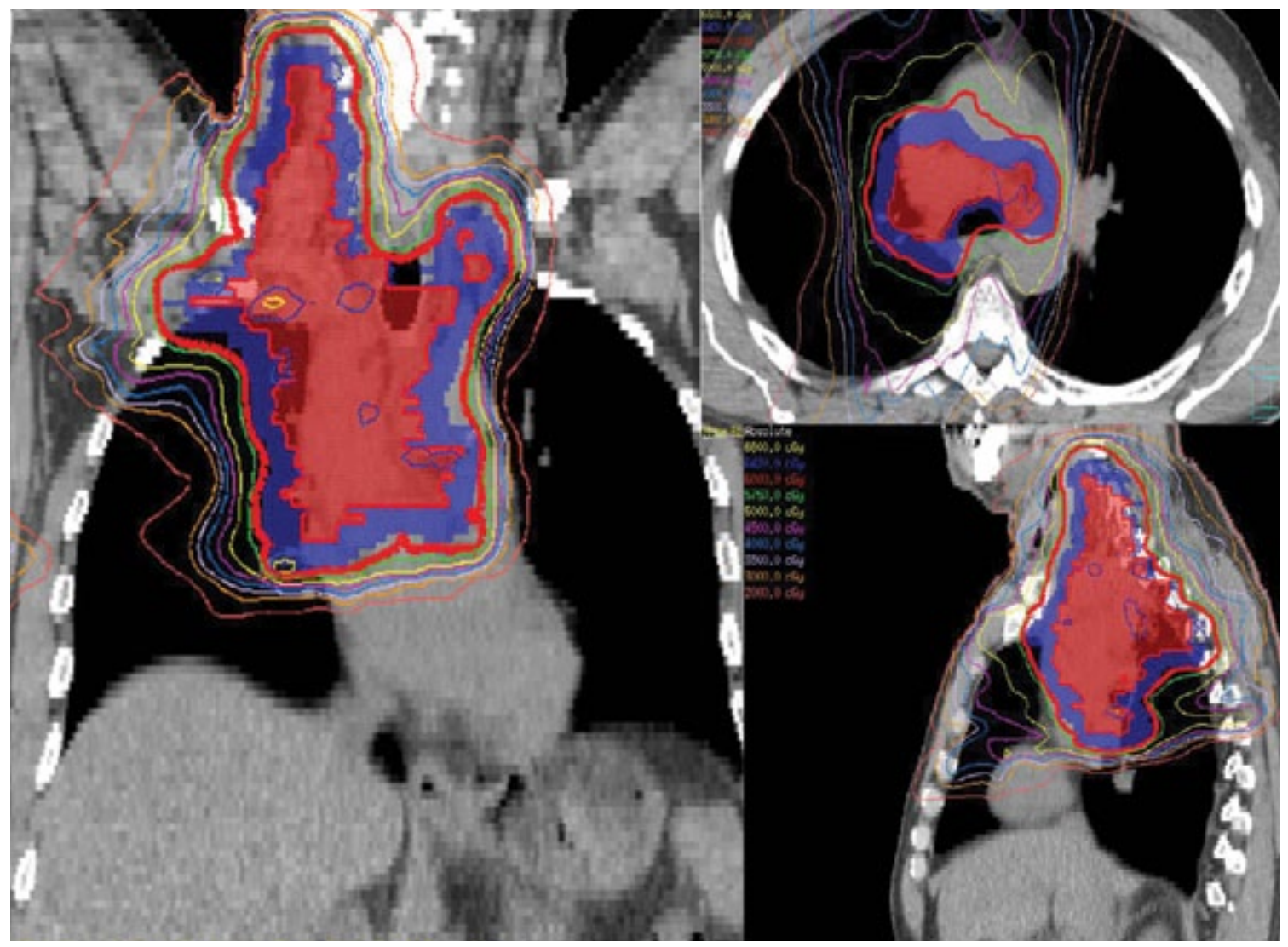

FIG. 1. IMRT with a definitive dose of $60 \mathrm{~Gy}$ to the PTV in 30 fractions using a 4D-CT-based ITV approach for a NSCLC patient with T4N3M0 disease.

tion, common sense would indicate that all locally advanced NSCLC patients would be treated with IMRT. The proper question might be which patients definitely need IMRT, aside from the patients who could be satisfactorily treated with both techniques. Bezjak et al. (43) published the Canadian Guidelines on lung IMRT and indicated a specific group of patients who could benefit the most from IMRT: tumors in close proximity to an OAR (e.g. the spinal cord), a large volume of OAR in jeopardy based on tumor/target volume (e.g. bilateral nodal volume), and an additional dose escalation requirement to avoid increased toxicity in normal tissue.

\section{UTILISATION OF MOTION AWARENESS AND MANAGEMENT}

Target motion in correlation with the respiratory cycle is a major challenge for the ideal delivery of radiotherapy. The conventional approach is to both plan and deliver radiotherapy during a normal breathing pattern without any respiratory management, but using a larger estimated volume with an additional margin to compensate the unknown motion during treatment. The lung tumor motion and methods to cope with it have long been studied in order to consider this change in lung cancer treatment planning (44-46). The American Association of Physicists in Medicine (AAPM) Task Group 76 guidelines summarised the adequate methods to account for this obscure motion by different methods: motion encompassing (slow CT scanning; combination of inhale and exhale breath-hold CT; and 4Dimensional-CT/respiration-correlated CT); respiratory gating (internal fiducial markers or external markers to signal respiration); breath hold (self- or device-controlled with or without respiratory monitoring); abdominal compression for shallow breathing; and real time tracking (47). The most accepted and user friendly method seems to be 4D-CT during normal breathing, which gives an average internal target volume (ITV) model to cover and compensate respiration-related tumor motion $(46,48-50)$. The ITV approach provides individualisation in prescription by designing patient- and motion-specific margins that incorporate the extent of tumor motion.

Since the motion could be managed with 4DCT and ITV utilisation, dose calculation was another concern in IMRT due to the fact that that motion information and change in density based on movement were not included in the calculation in a conventional setting. Additionally, breathing-related 


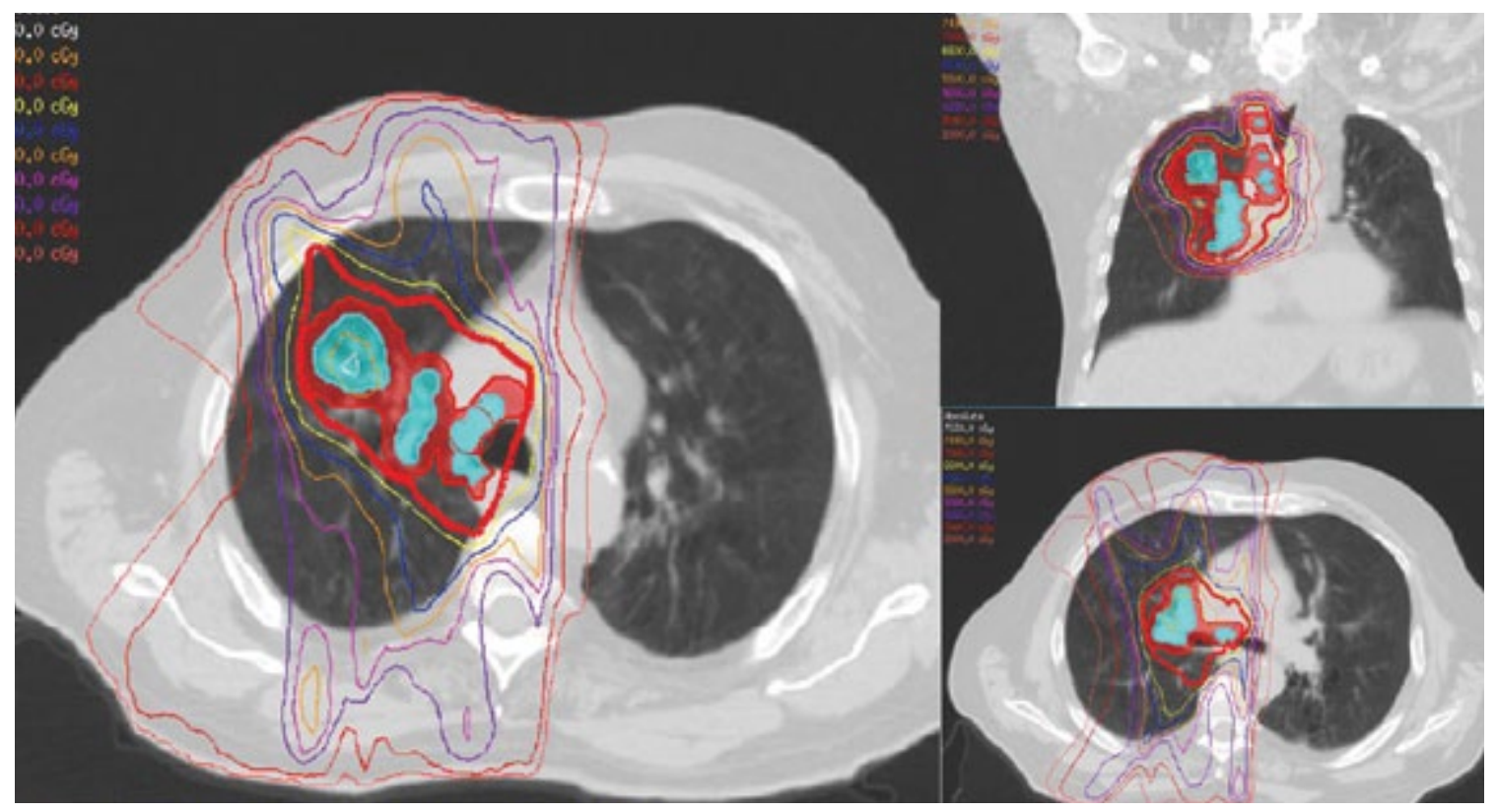

FIG. 2. IMRT with a definitive dose of $70 \mathrm{~Gy}$ to the PTV in 35 fractions using a 4D-CT-based ITV approach for a NSCLC patient with T2N2M0 disease.
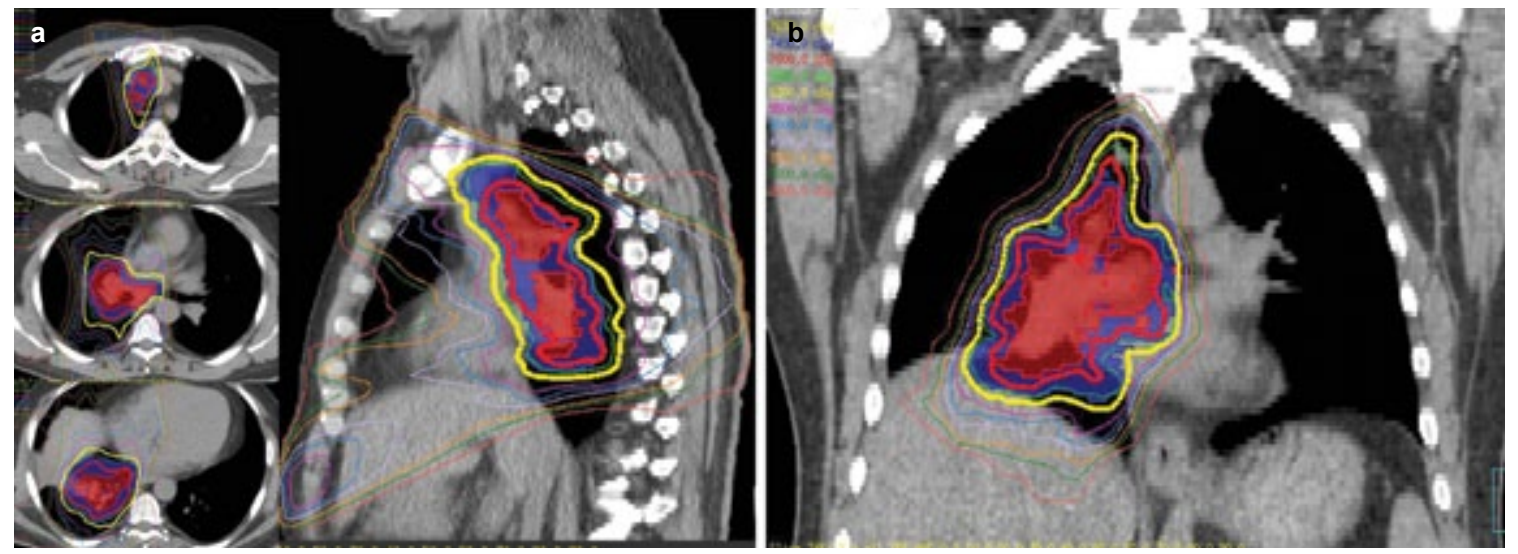

FIG. 3. a, b. IMRT-based simultaneous integrated boost to $70 \mathrm{~Gy}$ (2 Gy/fraction/day) to integrated gross tumor volume while keeping the conventional PTV dose of $63 \mathrm{~Gy}$ in 35 fractions using a 4D-CT based ITV approach for a NSCLC patient with T3N2M0 disease; axial and sagittal images (a). IMRTbased simultaneous integrated boost to $70 \mathrm{~Gy}$ ( 2 Gy/fraction/day) to integrated gross tumor volume while keeping the conventional PTV dose of 63 Gy in 35 fractions using a 4D-CT based ITV approach for a NSCLC patient with T3N2M0 disease; coronal image (b).

intra-fraction organ motion was an issue. However, the plans after 4DCT simulation are generally reconstructed on an average intensity projection dataset and dose calculations are performed with treatment planning software including modern dose algorithms based on heterogeneity correction, such as Monte Carlo, collapsed-cone, convolution/superposition, anisotropic analytical algorithm, and Acuros ${ }^{\circledR}$ XB (51-55). Additionally, Bortfeld et al. (56) showed that the effect of organ motion during IMRT does not cause systematic errors in dose delivery and it averages the dose distribution without motion over the path of the tumor motion, and this is actually not different from conventional beams. The vital component in planning is $4 \mathrm{D}-\mathrm{CT}$ simulation, which should be used if available. If it is not available, other alternative options to produce an average image of the tumor at all respiratory phases, such as spiral CT or slow CT scanning, need to be considered. Based on the complex extent of dose shaping and conformity requirement in IMRT than 3DCRT, it ought to be expressed that motion awareness and 4D planning support to identify the margins of the runaway target are more critical for IMRT than for conventional 3D-CRT. Therefore, the planned IMRT doses with motion awareness including a 4DCT dataset and current heterogeneity correction algorithms definitely represent the doses delivered. 


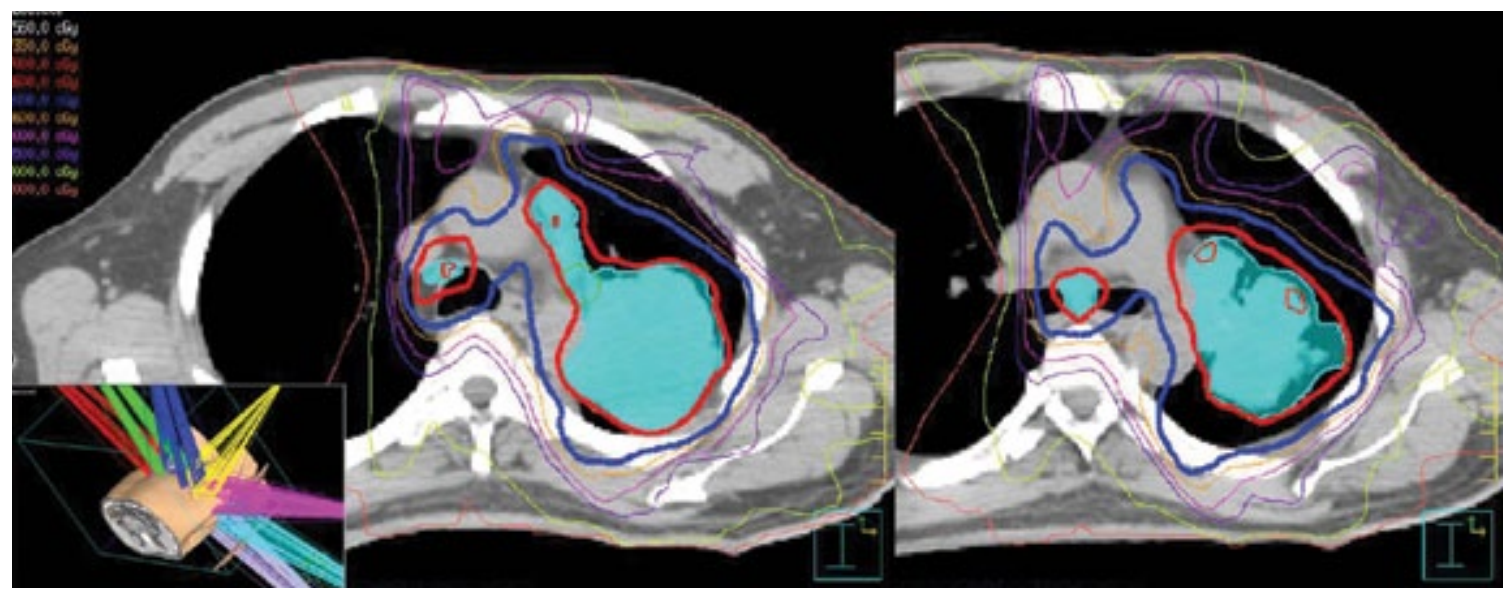

FIG. 4. IMRT-based simultaneous integrated boost to $66 \mathrm{~Gy}$ (2.2 Gy/fraction/day) to an integrated gross tumor volume, while keeping the conventional PTV dose of $60 \mathrm{~Gy}$ (2 Gy/fraction/day) in 30 fractions using a 4D-CT-based ITV approach for an NSCLC patient with T3N3M0 disease.

\section{IRRADIATION OF LARGE VOLUMES TO LOW DOSES WITH IMRT}

As is well known, the integral dose is not expected to decrease with IMRT, and the total dose is deposited to the total volume of treated area, but mainly in the lung parenchyma, while reducing OAR doses in the esophagus and spinal cord. Therefore, the lower doses spread around as lung V5 or V10 increase in comparison to 3DCRT. In treatment plan evaluation, these low dose parameters are not considered alone as critical while there are universally set values to ensure among all other lung criteria. Jin et al. (57) studied MD Anderson Cancer Center data from 576 inoperable NSCLC patients to determine dose-volume thresholds for the risk of treatment-related pneumonitis after definitive radiotherapy. The incidence of grade 3 or more treatment-related pneumonitis was found to be only $2 \%$ if the following dose-volume parameters could be achieved: V $5 \leq 60 \%$, V $10 \leq 42 \%$, V 20 $\leq 25 \%$, V $25 \leq 20 \%$, V $35 \leq 15 \%$, and V $50 \leq 10 \%$. Wang et al. (58) noted a collinearity between V5 and V20 for predicting the risk of pneumonia, but they could not define a specific DVH parameter for V5. Shi et al. (59) at Peking University shared their analysis associated with severe acute radiation pneumonitis in NSCLC patients treated with concurrent chemotherapy and IMRT. They reported that keeping V10 below $50 \%$ (pneumonia risk: V10 $\leq 50 \% ; 5.7 \%$ versus V10 $>50 \%$; $29.2 \%$ ) was a useful indicator for avoiding pneumonitis. Since the significance is not yet known how hazardous of irradiating large volumes to low doses, based on the sparse data of V 5 and V10 doses regarding pneumonitis, many centers try to keep V5 $<60-65 \%$ and V $10<45 \%$ in chemoradiotherapy protocols (V5 $<55 \%$ and $\mathrm{V} 10<40 \%$ in neoadjuvant setting to surgery), in addition to achieving dose constraints of mean lung dose and V20. The number of IMRT treatment fields is recommended to be limited to 5-7 to reduce lung low dose exposure (60).

\section{CONCLUSION}

3DCRT has been a trusted method for a long time and has well-known drawbacks, most of which could be improved by IMRT. One cannot claim that IMRT is the current standard in NSCLC treatment, but almost all patients could benefit to a degree in OAR sparing, dose coverage conformality, or dose escalation. The current literature and our own institutional experience justify increasing the use of IMRT, including 4D imaging plus PET CT, and encourage us to proceed with the applicable knowledge and individualised dose escalation using advanced daily image guided radiotherapy $(1,15,19,42)$. Therefore, off clinical protocol, we recommend delivering 6070 Gy (Figures 1-4) to the planning target volume (PTV) in $2 \mathrm{~Gy} /$ fraction/day, or 60-63 Gy to the PTV in 1.8-2 Gy/fraction/day plus an individualised simultaneous integrated boost dose escalation to the iGTV to 70 Gy in $2-2.2$ Gy/fraction/ day with concurrent chemotherapy in patients with inoperable stage III NSCLC (1). If the patient is chemoradiotherapy ineligible with a poor performance status and is disposed for radiotherapy alone or for palliation, the prescription might also be individualised to deliver 37.5-45 Gy (Figure 5) to a PTV in 2.5-3 Gy/fraction/day plus an individualised simultaneous integrated boost dose escalation to the iGTV to 45-52.5 Gy in 3-3.5 Gy/fraction/day.

The most critical step in a radiation oncology department, based on "Primum non nocere", is to strictly evaluate its technical and physical capabilities to define the IMRT ability for delivering an optimal treatment plan including calculation of internal tumor motion (ideally 4DCT or equivalent techniques), treatment planning software with an up-to-date het- 


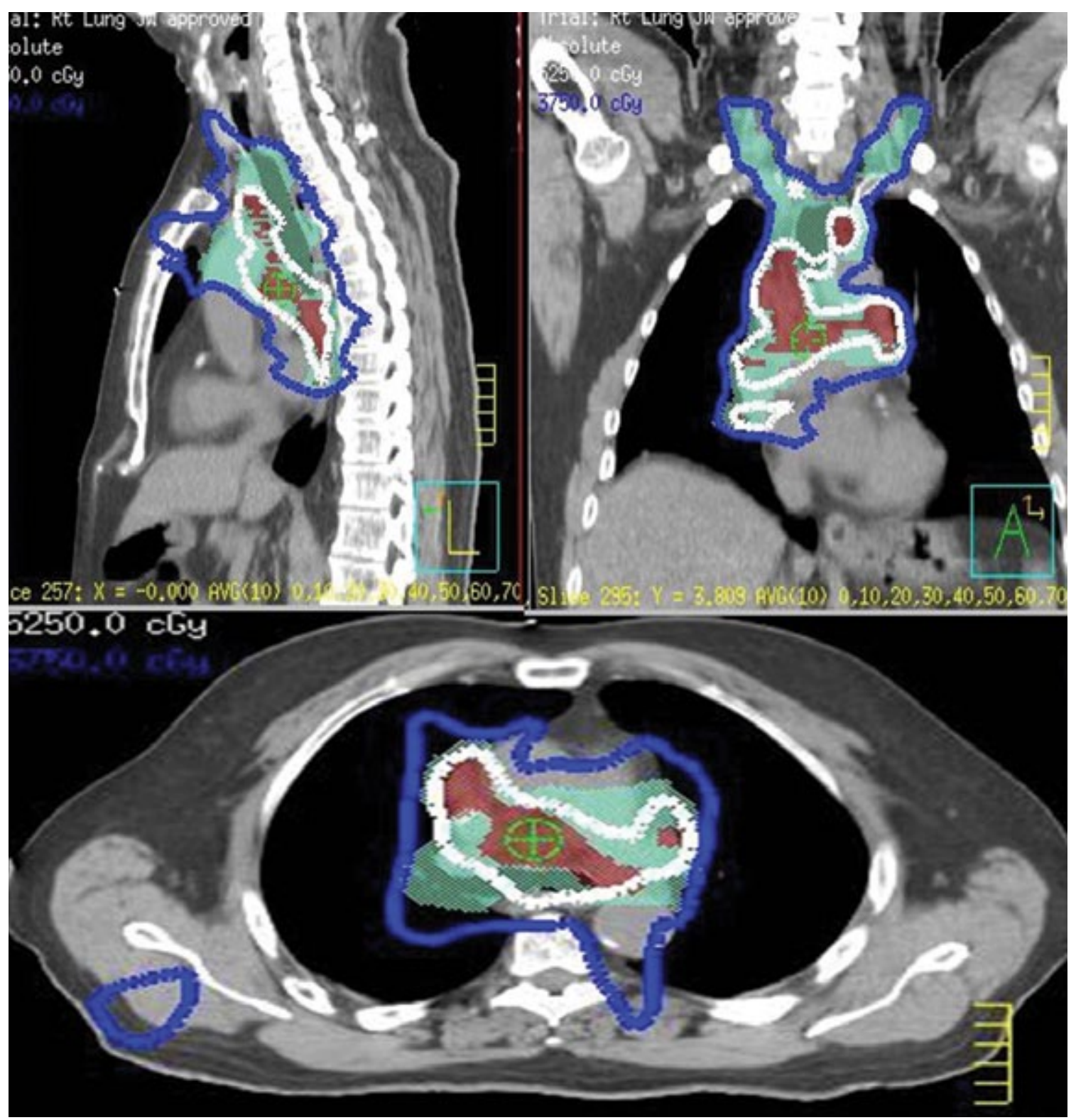

FIG. 5. IMRT-based simultaneous integrated boost to $52.5 \mathrm{~Gy}$ (3.5 Gy/fraction/day) to an integrated gross tumor volume, while keeping the conventional PTV dose of 37.5 Gy (2.5 Gy/fraction/day) in 15 fractions using a 4D-CT-based ITV approach for an NSCLC patient treated with radiotherapy alone to provide two benefits as follows: a safer plan with lung constraints being met, and also a higher dose to the iGTV.

erogeneity correction algorithm, and daily image guidance. It is crucial to optimise and individualise therapeutic ratio of radiotherapy in our lung cancer patients with applicable cuttingedge technologies.

Peer-review: Externally peer-reviewed.

Author contributions: Concept - U.S., Y.B., J.W.W., E.T.; Design - U.S., Y.B., J.W.W., E.T.; Supervision - U.S., E.T.; Resource - U.S., Y.B., J.W.W., E.T.; Materials - U.S., Y.B., J.W.W., E.T.; Data Collection\&/or Processing - U.S., Y.B., J.W.W., E.T.; Analysis\&/or Interpretation - U.S., Y.B., E.T.; Literature Search - U.S., Y.B., E.T.; Writing - U.S., Y.B., E.T.; Critical Reviews - U.S., E.T.
Conflict of Interest: No conflict of interest was declared by the authors.

Financial Disclosure: The authors declared that this study has received no financial support.

\section{REFERENCES}

1. Selek U, Chang JY. Evolution of modern-era radiotherapy strategies for unresectable advanced non-small-cell lung cancer. Lung Cancer Management 2013;2:213-25.[CrossRef]

2. Auperin A, Le Pechoux C, Rolland E, Curran WJ, Furuse K, Fournel P, et al. Meta-analysis of concomitant versus sequential radiochemotherapy 
in locally advanced non-small-cell lung cancer. J Clin Oncol. 2010 May 1;28(13):2181-90. PubMed PMID: 20351327. Epub 2010/03/31. eng.

3. Curran WJ, Jr., Paulus R, Langer CJ, Komaki R, Lee JS, Hauser S, et al. Sequential vs. concurrent chemoradiation for stage III non-small cell lung cancer: randomized phase III trial RTOG 9410. J Natl Cancer Inst 2011;103:1452-60. [CrossRef]

4. Jeremic B, Shibamoto Y, Acimovic L, Milisavljevic S. Hyperfractionated radiation therapy with or without concurrent low-dose daily carboplatin/etoposide for stage III non-small-cell lung cancer: a randomized study. J Clin Oncol 1996;14:1065-70.

5. Furuse K, Fukuoka M, Kawahara M, Nishikawa H, Takada Y, Kudoh S, et al. Phase III study of concurrent versus sequential thoracic radiotherapy in combination with mitomycin, vindesine, and cisplatin in unresectable stage III non-small-cell lung cancer. J Clin Oncol 1999;17:2692-9.

6. Zatloukal P, Petruzelka L, Zemanova M, Havel L, Janku F, Judas L, et al. Concurrent versus sequential chemoradiotherapy with cisplatin and vinorelbine in locally advanced non-small cell lung cancer: a randomized study. Lung Cancer 2004;46:87-98. [CrossRef]

7. Fournel P, Robinet G, Thomas P, Souquet PJ, Lena H, Vergnenegre A, et al. Randomized phase III trial of sequential chemoradiotherapy compared with concurrent chemoradiotherapy in locally advanced nonsmall-cell lung cancer: Groupe Lyon-Saint-Etienne d'Oncologie Thoracique-Groupe Francais de Pneumo-Cancerologie NPC 95-01 Study. $J$ Clin Oncol 2005;23:5910-7. [CrossRef]

8. Topkan E, Parlak C, Topuk S, Guler OC, Selek U. Outcomes of aggressive concurrent radiochemotherapy in highly selected septuagenarians with stage IIIB non-small cell lung carcinoma: retrospective analysis of 89 patients. Lung Cancer 2013;81:226-30. [CrossRef]

9. Machtay M, Bae K, Movsas B, Paulus R, Gore EM, Komaki R, et al. Higher biologically effective dose of radiotherapy is associated with improved outcomes for locally advanced non-small cell lung carcinoma treated with chemoradiation: An analysis of the Radiation Therapy Oncology Group. Int J Radiat Oncol Biol Phys 2012;82:425-34. [CrossRef]

10. Machtay M, Paulus R, Moughan J, Komaki R, Bradley JE, Choy H, et al. Defining local-regional control and its importance in locally advanced non-small cell lung carcinoma. $J$ Thorac Oncol 2012;7:716-22. [CrossRef]

11. Rengan R, Rosenzweig KE, Venkatraman E, Koutcher LA, Fox JL, Nayak R, et al. Improved local control with higher doses of radiation in large-volume stage III non-small-cell lung cancer. Int J Radiat Oncol Biol Phys 2004;60:741-7. [CrossRef]

12. Wang L, Correa CR, Zhao L, Hayman J, Kalemkerian GP, Lyons S, et al. The effect of radiation dose and chemotherapy on overall survival in 237 patients with Stage III non-small-cell lung cancer. Int J Radiat Oncol Biol Phys 2009;73:1383-90. [CrossRef]

13. Tyldesley S, Boyd C, Schulze K, Walker H, Mackillop WJ. Estimating the need for radiotherapy for lung cancer: an evidence-based, epidemiologic approach. Int J Radiat Oncol Biol Phys 2001;49:973-85. [CrossRef]

14. Tyldesley S, Delaney G, Foroudi F, Barbera L, Kerba M, Mackillop W. Estimating the need for radiotherapy for patients with prostate, breast, and lung cancers: verification of model estimates of need with radiotherapy utilization data from British Columbia. Int J Radiat Oncol Biol Phys 2011;79:1507-15. [CrossRef]

15. Yom SS, Liao Z, Liu HH, Tucker SL, Hu CS, Wei X, et al. Initial evaluation of treatment-related pneumonitis in advanced-stage non-small-cell lung cancer patients treated with concurrent chemotherapy and intensitymodulated radiotherapy. Int J Radiat Oncol Biol Phys 2007;68:94-102. [CrossRef]

16. Graham MV, Purdy JA, Emami B, Harms W, Bosch W, Lockett MA, et al. Clinical dose-volume histogram analysis for pneumonitis after 3D treatment for non-small cell lung cancer (NSCLC). Int $J$ Radiat Oncol Biol Phys 1999;45:323-9. [CrossRef]
17. Marks LB, Bentzen SM, Deasy JO, Kong FM, Bradley JD, Vogelius IS, et al. Radiation dose-volume effects in the lung. Int J Radiat Oncol Biol Phys 2010;76(3 Suppl):S70-6. [CrossRef]

18. Marks LB, Yorke ED, Jackson A, Ten Haken RK, Constine LS, Eisbruch A, et al. Use of normal tissue complication probability models in the clinic. Int J Radiat Oncol Biol Phys 2010;76(3 Suppl):S10-9. [CrossRef]

19. Kong FM, Ritter T, Quint DJ, Senan S, Gaspar LE, Komaki RU, et al. Consideration of dose limits for organs at risk of thoracic radiotherapy: atlas for lung, proximal bronchial tree, esophagus, spinal cord, ribs, and brachial plexus. Int J Radiat Oncol Biol Phys 2011;81:1442-57. [CrossRef]

20. Sundar IK, Mullapudi N, Yao H, Spivack SD, Rahman I. Lung cancer and its association with chronic obstructive pulmonary disease: update on nexus of epigenetics. Curr Opin Pulm Med. 2011;17:279-85. [CrossRef]

21. Semrau S, Klautke G, Fietkau R. Baseline cardiopulmonary function as an independent prognostic factor for survival of inoperable non-smallcell lung cancer after concurrent chemoradiotherapy: a single-center analysis of 161 cases. Int J Radiat Oncol Biol Phys 2011;79:96-104. [CrossRef]

22. Cerfolio RJ, Talati A, Bryant AS. Changes in pulmonary function tests after neoadjuvant therapy predict postoperative complications. Ann Thorac Surg 2009;88:930-5.[CrossRef]

23. Kepka L, Bujko K, Orlowski TM, Jagiello R, Salata A, Matecka-Nowak $\mathrm{M}$, et al. Cardiopulmonary morbidity and quality of life in non-small cell lung cancer patients treated with or without postoperative radiotherapy. Radiother Oncol 2011;98:238-43. [CrossRef]

24. Bradley JD, Bae K, Graham MV, Byhardt R, Govindan R, Fowler J, et al. Primary analysis of the phase II component of a phase I/II dose intensification study using three-dimensional conformal radiation therapy and concurrent chemotherapy for patients with inoperable non-small-cell lung cancer: RTOG 0117. J Clin Oncol 2010;28:2475-80. [CrossRef]

25. Schild SE, McGinnis WL, Graham D, Hillman S, Fitch TR, Northfelt D, et al. Results of a Phase I trial of concurrent chemotherapy and escalating doses of radiation for unresectable non-small-cell lung cancer. Int $J$ Radiat Oncol Biol Phys 2006;65:1106-11. [CrossRef]

26. Socinski MA, Rosenman JG, Halle J, Schell MJ, Lin Y, Russo S, et al. Dose-escalating conformal thoracic radiation therapy with induction and concurrent carboplatin/paclitaxel in unresectable stage IIIA/B nonsmall cell lung carcinoma: a modified phase I/II trial. Cancer 2001;92:1213-23. [CrossRef]

27. Kong FM, Ten Haken RK, Schipper MJ, Sullivan MA, Chen M, Lopez $\mathrm{C}$, et al. High-dose radiation improved local tumor control and overall survival in patients with inoperable/unresectable non-small-cell lung cancer: long-term results of a radiation dose escalation study. Int $J$ Radiat Oncol Biol Phys 2005;63:324-33. [CrossRef]

28. Zhao L, West BT, Hayman JA, Lyons S, Cease K, Kong FM. High radiation dose may reduce the negative effect of large gross tumor volume in patients with medically inoperable early-stage non-small cell lung cancer. Int J Radiat Oncol Biol Phys 2007;68:103-10. [CrossRef]

29. Yuan S, Sun X, Li M, Yu J, Ren R, Yu Y, et al. A randomized study of involved-field irradiation versus elective nodal irradiation in combination with concurrent chemotherapy for inoperable stage III nonsmall cell lung cancer. Am J Clin Oncol 2007;30:239-44. [CrossRef]

30. Bradley J, Paulus R, Komaki R, Masters G, Forster K, Schild SE, et al., editors. A randomized phase III comparison of standard-dose (60 Gy) versus high-dose (74 Gy) conformal chemoradiotherapy +/- cetuximab for stage IIIa/IIIb non-small cell lung cancer: Preliminary findings on radiation dose in RTOG 0617 (late-breaking abstract 2). Presented at the 53rd Annual Meeting of the American Society of Radiation Oncology, October 2-6, 2011, Miami, FL.2011.

31. Cox JD. Are the results of RTOG 0617 mysterious? Int J Radiat Oncol Biol Phys 2012;82:1042-4. [CrossRef] 
32. Grills IS, Yan D, Martinez AA, Vicini FA, Wong JW, Kestin LL. Potential for reduced toxicity and dose escalation in the treatment of inoperable non-small-cell lung cancer: A comparison of intensity-modulated radiation therapy (IMRT), 3D conformal radiation, and elective nodal irradiation. Int J Radiat Oncol Biol Phys 2003;57:875-90. [CrossRef]

33. Underwood LJ, Murray BR, Robinson DM, Field GC, Roa WH. An evaluation of forward and inverse radiotherapy planning using HelaxTMS (version 6.0) for lung cancer patients treated with RTOG 93-11 dose-escalation protocol. Med Dosim 2003;28:167-70. [CrossRef]

34. Liu HH, Wang X, Dong L, Wu Q, Liao Z, Stevens CW, et al. Feasibility of sparing lung and other thoracic structures with intensity-modulated radiotherapy for non-small-cell lung cancer. Int $J$ Radiat Oncol Biol Phys 2004;58:1268-79. [CrossRef]

35. Murshed H, Liu HH, Liao Z, Barker JL, Wang X, Tucker SL, et al. Dose and volume reduction for normal lung using intensity-modulated radiotherapy for advanced-stage non-small-cell lung cancer. Int J Radiat Oncol Biol Phys 2004;58:1258-67. [CrossRef]

36. Manon RR, Jaradat H, Patel R, Zhang T, Fenwick J, Tome W, et al. Potential for radiation therapy technology innovations to permit dose escalation for non-small-cell lung cancer. Clin Lung Cancer 2005;7:107-13. [CrossRef]

37. Schwarz M, Alber M, Lebesque JV, Mijnheer BJ, Damen EM. Dose heterogeneity in the target volume and intensity-modulated radiotherapy to escalate the dose in the treatment of non-small-cell lung cancer. Int $J$ Radiat Oncol Biol Phys 2005;62:561-70. [CrossRef]

38. Chapet O, Khodri M, Jalade P, N'Guyen D, Flandin I, D'Hombres A, et al. Potential benefits of using non coplanar field and intensity modulated radiation therapy to preserve the heart in irradiation of lung tumors in the middle and lower lobes. Radiother Oncol 2006;80:333-40. [CrossRef]

39. Christian JA, Bedford JL, Webb S, Brada M. Comparison of inverseplanned three-dimensional conformal radiotherapy and intensity-modulated radiotherapy for non-small-cell lung cancer. Int $J$ Radiat Oncol Biol Phys 2007;67:735-41. [CrossRef]

40. Mayo CS, Urie MM, Fitzgerald TJ, Ding L, Lo YC, Bogdanov M. Hybrid IMRT for treatment of cancers of the lung and esophagus. Int $J$ Radiat Oncol Biol Phys 2008;71:1408-18. [CrossRef]

41. Marnitz S, Stuschke M, Bohsung J, Moys A, Reng I, Wurm R, et al. Intraindividual comparison of conventional three-dimensional radiotherapy and intensity modulated radiotherapy in the therapy of locally advanced non-small cell lung cancer a planning study. Strahlenther Onkol 2002;178:651-8. [CrossRef]

42. Liao ZX, Komaki RR, Thames HD, Jr., Liu HH, Tucker SL, Mohan R, et al. Influence of technologic advances on outcomes in patients with unresectable, locally advanced non-small-cell lung cancer receiving concomitant chemoradiotherapy. Int J Radiat Oncol Biol Phys 2010;76: 775-81. [CrossRef]

43. Bezjak A, Rumble RB, Rodrigues G, Hope A, Warde P. Intensity-modulated radiotherapy in the treatment of lung cancer. Clin Oncol ( $R$ Coll Radiol) 2012;24:508-20. [CrossRef]

44. Seppenwoolde Y, Shirato H, Kitamura K, Shimizu S, van Herk M, Lebesque JV, et al. Precise and real-time measurement of 3D tumor motion in lung due to breathing and heartbeat, measured during radiotherapy. Int J Radiat Oncol Biol Phys 2002;53:822-34. [CrossRef]

45. Shirato H, Suzuki K, Sharp GC, Fujita K, Onimaru R, Fujino M, et al. Speed and amplitude of lung tumor motion precisely detected in four- dimensional setup and in real-time tumor-tracking radiotherapy. Int $J$ Radiat Oncol Biol Phys 2006;64:1229-36. [CrossRef]

46. Liu HH, Balter P, Tutt T, Choi B, Zhang J, Wang C, et al. Assessing respiration-induced tumor motion and internal target volume using fourdimensional computed tomography for radiotherapy of lung cancer. Int J Radiat Oncol Biol Phys 2007;68:531-40. [CrossRef]

47. Keall PJ, Mageras GS, Balter JM, Emery RS, Forster KM, Jiang SB, et al. The management of respiratory motion in radiation oncology report of AAPM Task Group 76. Med Phys 2006;33:3874-900. [CrossRef]

48. Chavaudra J, Bridier A. [Definition of volumes in external radiotherapy: ICRU reports 50 and 62]. Cancer Radiother 2001;5:472-8. [CrossRef]

49. Underberg RW, Lagerwaard FJ, Slotman BJ, Cuijpers JP, Senan S. Use of maximum intensity projections (MIP) for target volume generation in 4DCT scans for lung cancer. Int J Radiat Oncol Biol Phys 2005;63:253-60. [CrossRef]

50. Rietzel E, Liu AK, Chen GT, Choi NC. Maximum-intensity volumes for fast contouring of lung tumors including respiratory motion in 4DCT planning. Int J Radiat Oncol Biol Phys 2008;71:1245-52. [CrossRef]

51. Ahnesjo A. Collapsed cone convolution of radiant energy for photon dose calculation in heterogeneous media. Med Phys 1989;16:577-92. [CrossRef]

52. Aarup LR, Nahum AE, Zacharatou C, Juhler-Nottrup T, Knoos T, Nystrom $\mathrm{H}$, et al. The effect of different lung densities on the accuracy of various radiotherapy dose calculation methods: implications for tumour coverage. Radiother Oncol 2009;91:405-14. [CrossRef]

53. Bragg CM, Conway J. Dosimetric verification of the anisotropic analytical algorithm for radiotherapy treatment planning. Radiother Oncol 2006;81:315-23.[CrossRef]

54. Bush K, Gagne IM, Zavgorodni S, Ansbacher W, Beckham W. Dosimetric validation of Acuros XB with Monte Carlo methods for photon dose calculations. Med Phys 2011;38:2208-21. [CrossRef]

55. Vanderstraeten B, Reynaert N, Paelinck L, Madani I, De Wagter C, De Gersem W, et al. Accuracy of patient dose calculation for lung IMRT: A comparison of Monte Carlo, convolution/superposition, and pencil beam computations. Med Phys 2006;33:3149-58. [CrossRef]

56. Bortfeld T, Jokivarsi K, Goitein M, Kung J, Jiang SB. Effects of intrafraction motion on IMRT dose delivery: statistical analysis and simulation. Phys Med Biol 2002;47:2203-20. [CrossRef]

57. Jin H, Tucker SL, Liu HH, Wei X, Yom SS, Wang S, et al. Dose-volume thresholds and smoking status for the risk of treatment-related pneumonitis in inoperable non-small cell lung cancer treated with definitive radiotherapy. Radiother Oncol 2009;91:427-32. [CrossRef]

58. Wang D, Shi J, Liang S, Lu S, Qi X, Wang Q, et al. Dose-volume histogram parameters for predicting radiation pneumonitis using receiver operating characteristic curve. Clin Transl Oncol 2013;15:364-9. [CrossRef]

59. Shi A, Zhu G, Wu H, Yu R, Li F, Xu B. Analysis of clinical and dosimetric factors associated with severe acute radiation pneumonitis in patients with locally advanced non-small cell lung cancer treated with concurrent chemotherapy and intensity-modulated radiotherapy. Radiat Oncol 2010;5:35. [CrossRef]

60. Chang JY, Liu HH, Komaki R. Intensity modulated radiation therapy and proton radiotherapy for non-small cell lung cancer. Curr Oncol Rep 2005;7:255-9. [CrossRef] 